\title{
Treatment of osteochondral defects of the talus in children
}

\author{
Nicolò Martinelli · Carlo Bonifacini • \\ Giovanni Romeo $\cdot$ Elena Sartorelli
}

Received: 10 October 2013/ Accepted: 4 June 2014/Published online: 13 June 2014

(C) Springer-Verlag Berlin Heidelberg 2014

\section{Dear Editor,}

We read with interest the recently published article by Reilingh et al. [1]. Their paper presents the clinical outcome in skeletally immature children treated for osteochondral lesions of the talus. Among the results, the American Orthopaedic Foot and Ankle Society (AOFAS) score and the Short Form 36 (SF-36) were employed for the clinical assessment. When evaluating clinical outcome in children after a surgical procedure, the question is raised whether to use questionnaires specifically designed for children and adolescents or instruments like the SF-36 that are originally developed for adults. Clinical assessment scores such as AOFAS score and SF-36 may not capture the patient's perspective and may not accurately reflect how children relate to their usual environments regarding foot and ankle diseases [2, 3]. Although, SF-36 has been previously studied for its use in measuring health-related quality of life in adolescents and young adults [4], no data exist about psychometric properties of this questionnaire and the AOFAS score for paediatric foot and ankle diseases. For these reasons, it is important to recognise these limitations and to encourage the use of currently available measures specially developed for the foot and ankle diseases in children [5].

\section{References}

1. Reilingh ML, Kerkhoffs GM, Telkamp CJ, Struijs PA, van Dijk CN (2013) Treatment of osteochondral defects of the talus in children. Knee Surg sports Traumatol Arthrosc 18 [Epub ahead of print]

2. Guyton GP (2001) Theoretical limitations of the AOFAS scoring systems: an analysis using Monte Carlo modeling. Foot Ankle Int 22:779-787

3. Pless IB (1996) The SF-36: not suitable for children. Inj Prev 2:82-83

4. Jörngården A, Wettergen L, von Essen L (2006) Measuring healthrelated quality of life in adolescents and young adults: Swedish normative data for the SF-36 and the HADS, and the influence of age, gender, and method of administration. Health Qual Life Outcomes 4:91

5. Morris C, Doll H, Davies N, Wainwright A, Theologis T, Willett K, Fitzpatrick R (2009) The Oxford Ankle Foot Questionnaire for children: responsiveness and longitudinal validity. Qual Life Res 18:1367-1376 